\title{
Crystal structure of the $25 \mathrm{kDa}$ subunit of human cleavage factor $I_{m}$
}

\author{
Molly Coseno ${ }^{1}$, Georges Martin², Christopher Berger ${ }^{3}$, Gregory Gilmartin, \\ Walter Keller ${ }^{2}$ and Sylvie Doublié ${ }^{1, *}$
}

${ }^{1}$ Department of Microbiology and Department of Molecular Genetics, University of Vermont, Burlington, VT 05405, USA, ${ }^{2}$ Department of Cell Biology, Biozentrum, University of Basel, CH-4056 Basel, Switzerland and ${ }^{3}$ Molecular Physiology and Biophysics, University of Vermont, Burlington, VT 05405, USA

Received November 2, 2007; Revised February 8, 2008; Accepted February 9, 2008

\begin{abstract}
Cleavage factor $I_{m}$ is an essential component of the pre-messenger RNA 3'-end processing machinery in higher eukaryotes, participating in both the polyadenylation and cleavage steps. Cleavage factor $I_{m}$ is an oligomer composed of a small $25 \mathrm{kDa}$ subunit (CF $\left.I_{m} 25\right)$ and a variable larger subunit of either 59 , 68 or $72 \mathrm{kDa}$. The small subunit also interacts with RNA, poly(A) polymerase, and the nuclear poly(A)binding protein. These protein-protein interactions are thought to be facilitated by the Nudix domain of CF $I_{m} 25$, a hydrolase motif with a characteristic $\alpha / \beta / \alpha$ fold and a conserved catalytic sequence or Nudix box. We present here the crystal structures of human CF $I_{m} 25$ in its free and diadenosine tetraphosphate $\left(\mathrm{Ap}_{4} \mathrm{~A}\right)$ bound forms at 1.85 and $1.80 \AA$, respectively. CF $I_{m} 25$ crystallizes as a dimer and presents the classical Nudix fold. Results from crystallographic and biochemical experiments suggest that $C F I_{m} 25$ makes use of its Nudix fold to bind but not hydrolyze ATP and $A_{4} A$. The complex and apo protein structures provide insight into the active oligomeric state of $C F I_{m}$ and suggest a possible role of nucleotide binding in either the polyadenylation and/or cleavage steps of pre-messenger RNA 3 '-end processing.
\end{abstract}

\section{INTRODUCTION}

Pre-messenger RNA $3^{\prime}$-end processing in eukaryotes is a two-step reaction consisting of endonucleolytic cleavage of the pre-mRNA followed by addition of a poly(A) tail at the $3^{\prime}$ end of the upstream cleavage product (1-3). The coupling of these processing reactions relies on multiple protein-protein and protein-RNA interactions. The factors that are necessary and sufficient to reconstitute cleavage and polyadenylation in a mammalian in vitro system are poly(A) polymerase (PAP), cleavage and polyadenylation specificity factor (CPSF), cleavage stimulation factor $(\mathrm{CstF})$, cleavage factor $\mathrm{I}_{\mathrm{m}}\left(\mathrm{CF} \mathrm{I}_{\mathrm{m}}\right)$, cleavage factor $\mathrm{II}_{\mathrm{m}}\left(\mathrm{CF} \mathrm{II}_{\mathrm{m}}\right)$ and the nuclear poly $(\mathrm{A})$ binding protein 1 (PABPN1). The recruitment of the mammalian polyadenylation machinery to the pre-mRNA relies on the recognition of conserved sequence elements, such as the highly conserved hexamer AAUAAA recognized by CPSF and a U-rich sequence downstream of the cleavage site recognized by CstF. Additionally a set of UGUA elements, a third sequence element found upstream of the cleavage site and not as universally conserved, is recognized by CF $\mathrm{I}_{\mathrm{m}}(4,5)$. Upon completion of the processing steps the mRNA can be efficiently transported out of the nucleus into the cytoplasm. Homologs of CF I subunits are also found in cDNA databases of Caenorabditis elegans, Drosophila melanogaster and plants.

$\mathrm{CF} \mathrm{I}_{\mathrm{m}}$ is an oligomer composed of a small $25 \mathrm{kDa}$ subunit ( $\mathrm{CF} \mathrm{I}_{\mathrm{m}} 25$, also referred to as CPSF5 or NUDT21) and a larger subunit of either 59,68 or $72 \mathrm{kDa}(6)$. The three larger subunits share substantial sequence homology. They are encoded on two different genes and the $72 \mathrm{kDa}$ subunit is a splice variant of the $68 \mathrm{kDa}$ polypeptide. $\mathrm{CF}_{\mathrm{m}}$ can be reconstituted in vitro from the 25 - and $68 \mathrm{kDa}$ subunits (6). CF $\mathrm{I}_{\mathrm{m}}$, in addition to having a role in regulation of poly(A) site recognition, is also involved in stabilizing CPSF at the conserved hexamer, enhances the rate of poly (A) site cleavage in vitro, and has been shown to interact with PAP and PABPN1 via its $25 \mathrm{kDa}$ subunit (7). Furthermore $\mathrm{CF} \mathrm{I}_{\mathrm{m}}$ also interacts with splicing factors, indicating a role in communicating between different RNA-processing complexes (8).

Much of what we know about complex formation of processing factors on the pre-mRNA and its regulation

\footnotetext{
*To whom correspondence should be addressed. Tel: +1 802656 9531; Fax: +1 802656 8749; Email: sdoublie@uvm.edu 


$\begin{array}{ll}\text { H.sapiens CF Im25 } & \text { 3BAP } \\ \text { E. faecalis MuT T } & \text { 2FML } \\ \text { E.coli MuT T PPHase } & \text { 1MUT } \\ \text { D.radiodurans } 1025 \text { Ap4A hydrolase } & \text { 1SU2 } \\ \text { H.sapiens oxo-purine hydrolase } & 1 \mathrm{IRY} \\ \text { T. thermophilus ADP-ribose PPase } & 1 \mathrm{~V} 8 \mathrm{M} \\ \text { E.coll ADP-ribose PPase } & 1 \mathrm{GOS} \\ \text { H.sapiens ADP-sugar PPase } & \text { 2DSB } \\ \text { H.sapiens Ap4A hydrolase } & 1 \mathrm{XSA} \\ \text { E.coli putative hydrolase } & \text { 2FKB } \\ \text { X.laevis nucl. snoRNA decapping hydrolase } & \text { 2A8R } \\ \text { S.pombe Dcp2p decapping hydrolase } & \text { 2A6T } \\ \text { L. angustifolius L. Ap4A hydrolase } & 1 \mathrm{~F} 3 Y \\ \text { E.coli GDP-mannose mannosyl hydrolase } & \text { 1RYA }\end{array}$

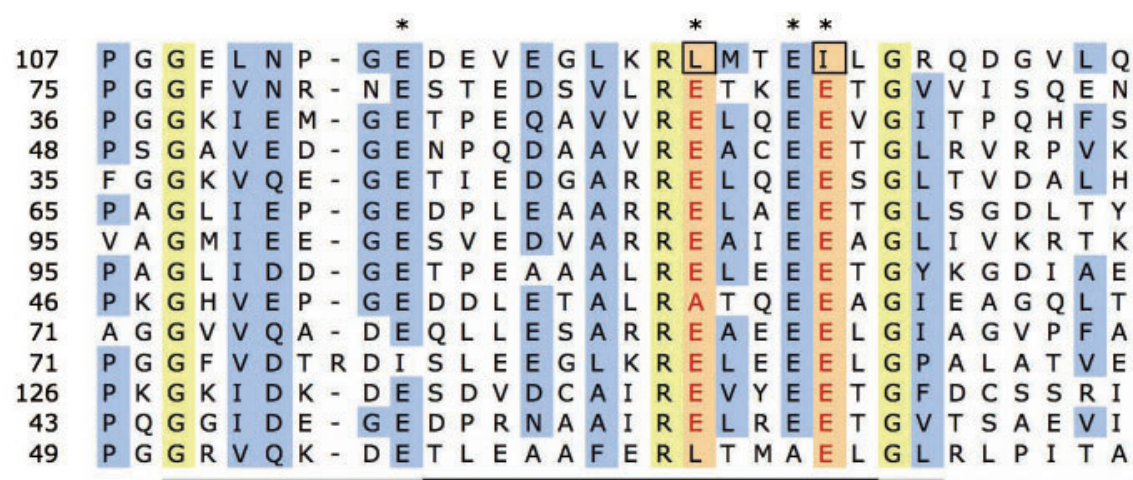

Figure 1. Sequence alignment of $C F I_{m} 25$ with Nudix proteins. ClustalW sequence alignment of CF $I_{m} 25$ and Nudix proteins of known structure (44). PDB ID codes are shown to the right of the enzyme names followed by the residue number of the first amino acid. The position of the Nudix box is indicated below the alignment as a grey/black bar where the black part marks the position of helix $\alpha 2$. Residues are on a light blue background if over $70 \%$ conserved and are on yellow background if invariant. The two catalytic glutamates conserved in most Nudix enzymes are displayed in red font on light orange background. L124 and $\mathrm{I} 128$, which are found in place of the conserved glutamates, are boxed in the CF $\mathrm{I}_{\mathrm{m}} 25$ sequence. The abbreviations are defined as: PPHase for pyrophosphohydrolase and PPase for pyrophosphatase.

has been investigated biochemically. Structural characterization of individual and multicomponent processing factors will elucidate the domain interactions important for the $3^{\prime}$ pre-mRNA processing mechanism that cannot be deciphered by biochemical means. The structure of the $25 \mathrm{kDa}$ subunit of CF $\mathrm{I}_{\mathrm{m}}\left(\mathrm{CF} \mathrm{I}_{\mathrm{m}} 25\right)$ will help further define the domains important for substrate and protein interactions.

The structure of CF $\mathrm{I}_{\mathrm{m}} 25$ will also allow us to investigate the function of a Nudix domain present in this protein. The first Nudix protein to be characterized enzymatically and structurally was Escherichia coli MutT (9). Nudix proteins are generally characterized as housekeeping enzymes due to their role in hydrolysis of substrates described as nucleoside diphosphate linked to another moiety $\mathbf{X}$, many of which are potentially toxic molecules $(10,11)$. Nudix proteins have a conserved Nudix fold consisting of an $\alpha / \beta / \alpha$ sandwich. Within the Nudix fold the consensus sequence of the Nudix box is $\mathrm{GX}_{5} \mathrm{EX}_{7}$ REUXEEXGU, where $\mathrm{U}$ is a hydrophobic residue and $\mathrm{X}$ is any residue, and folds into a loop- $\alpha$ helix-loop structure (9). Interestingly, the Nudix box in CF $\mathrm{I}_{\mathrm{m}} 25$ lacks two of the four conserved glutamate residues, three of which were shown to be important for catalysis (Figure 1) (12).

In this study we present the crystal structure of human $\mathrm{CF} \mathrm{I}_{\mathrm{m}} 25$ alone and in complex with diadenosine tetraphosphate $\left(\mathrm{Ap}_{4} \mathrm{~A}\right)$. CF $\mathrm{I}_{\mathrm{m}} 25$ crystallizes as a dimer, which is also the oligomeric state of the protein in solution. The $\mathrm{CF} \mathrm{I}_{\mathrm{m}} 25$ structure presents the classic Nudix $\alpha / \beta / \alpha$ fold and harbors residues outside of the Nudix core that could potentiate ligand binding. Structural and biochemical evidence suggests that $\mathrm{CF} \mathrm{I}_{\mathrm{m}} 25$ binds, but does not hydrolyze, mono and di-adenosine nucleotides.

\section{MATERIALS AND METHODS}

\section{Protein purification}

The construction of the plasmid expressing the $25 \mathrm{kDa}$ subunit of human cleavage factor $\mathrm{I}_{\mathrm{m}}\left(\mathrm{CF} \mathrm{I}_{\mathrm{m}}\right)$ with an
N-terminal 6xHis tag was previously described (7). The cDNA of CF $\mathrm{I}_{\mathrm{m}} 25$ was subsequently cloned into a Gateway ${ }^{\circledR}$ vector with a dual 6xHis-maltose binding protein (MBP) affinity tag provided by Dr David S. Waugh (National Cancer Institute, Frederick, MD) (13). The following primers were used in the polymerase chain reaction (PCR): 5'-GAG AAC CTG TAC TTC CAG GGT ATG TCT GTG GTA CCG CCC-3', 5'-GGG GAC CAC TTT GTA CAA GAA AGC TGG GTT ATT AGT TGT AAA TAA AAT TGA A- $3^{\prime}$ and $5^{\prime}$-GGGG ACA AGT TTG TAC AAA AAA GCA GGC TCG GAG AAC CTG TAC TTC CAG-3'. CF I 25 (227 amino acids) was then expressed in Rosetta (DE3) pLysS cells (Novagen) and grown in LB medium for $24 \mathrm{~h}$ at $25^{\circ} \mathrm{C}$ following induction with $0.4 \mathrm{mM}$ IPTG. The protein was purified on Nickel NTA beads (Qiagen), followed by a Tobacco etch virus (Tev) protease cleavage step, and cation exchange on a Resource $\mathrm{S}$ column (GE Healthcare): Cells were lysed at $4^{\circ} \mathrm{C}$ by sonication in a buffer containing $20 \mathrm{mM}$ Tris- $\mathrm{HCl} \mathrm{pH} 8.0,200 \mathrm{mM} \mathrm{NaCl}$, and a protease inhibitor tablet (Roche). The lysate was centrifuged at $12000 \times g$ and incubated with Ni-NTA beads (Qiagen) for $1 \mathrm{~h}$ at $4^{\circ} \mathrm{C}$. Protein was eluted with lysis buffer containing $100-500 \mathrm{mM}$ imidazole. Pooled fractions were dialyzed into $10 \%$ (v/v) glycerol, $20 \mathrm{mM}$ Tris$\mathrm{HCl} \mathrm{pH} 7.5$ and $50 \mathrm{mM} \mathrm{KCl}$. CF $\mathrm{I}_{\mathrm{m}} 25$ was cleaved from the MBP tag by the addition of equimolar amounts of Tev protease. MBP and Tev were then separated from $\mathrm{CF}$ $\mathrm{I}_{\mathrm{m}} 25$ by elution with a $50 \mathrm{mM}-1 \mathrm{M} \mathrm{KCl}$ gradient at $\mathrm{pH} 7.5$ on a Resource S column (GE Healthcare). The selenomethionyl protein was produced by inhibiting methionine biosynthesis in E. coli (14) and purified as described earlier. Proteins were concentrated to about $6-20 \mathrm{mg} / \mathrm{ml}$ (Millipore Amicon Ultra-15), flash frozen and stored at $-80^{\circ} \mathrm{C}$.

\section{Crystallization}

CF $I_{m} 25$ crystals were initially obtained with the sitting drop method in a 96-well tray format. Sitting drops were set up with a 925 PC Workstation (Gilson) by mixing 
Table 1. Data collection and refinement statistics

\begin{tabular}{|c|c|c|c|c|}
\hline Data collection & Se-Peak & Se-Edge & Se-Remote & $\mathrm{Ap}_{4} \mathrm{~A}$ complex \\
\hline $\begin{array}{l}\text { Wavelength }(\AA) \\
\text { Resolution }(\AA)\end{array}$ & $\begin{array}{l}0.97923 \\
30-1.82(1.89-1.82)^{\mathrm{a}}\end{array}$ & $\begin{array}{l}0.97939 \\
30-1.85(1.92-1.85)^{\mathrm{a}}\end{array}$ & $\begin{array}{l}0.97166 \\
30-1.90(1.97-1.90)^{\mathrm{a}}\end{array}$ & $\begin{array}{l}0.9 \\
15-1.80(1.86-1.80)^{\mathrm{a}}\end{array}$ \\
\hline $\begin{array}{l}\text { PDB ID Code } \\
\text { Number of atoms } \\
\text { Protein (non-hydrogen) } \\
\text { Water } \\
R_{\text {work }} \\
R_{\text {free }} \\
\text { r.m.s.d. bond distances }(\AA) \\
\text { r.m.s.d. bond angles }\left(^{\circ}\right)\end{array}$ & $\begin{array}{l}3 \mathrm{BAP} \\
1649 \\
167 \\
0.212 \\
0.234 \\
0.005 \\
1.320\end{array}$ & & & $\begin{array}{l}3 \mathrm{BHO} \\
\\
1663 \\
169 \\
0.202 \\
0.225 \\
0.004 \\
1.269\end{array}$ \\
\hline $\begin{array}{l}\text { Ramachandran plot } \\
\text { Most favored region (\%) } \\
\text { Additionally allowed }(\%) \\
\text { Generously allowed (\%) } \\
\text { Disallowed (\%) }\end{array}$ & $\begin{array}{l}92.0 \\
8.0 \\
0 \\
0\end{array}$ & & & $\begin{array}{l}92.9 \\
7.1 \\
0 \\
0\end{array}$ \\
\hline $\begin{array}{l}\text { Average B factor all atoms }\left(\AA^{2}\right) \\
\text { Wilson B-factor } \\
\text { Protein only } \\
\text { Water only } \\
\text { Ligand only }\end{array}$ & $\begin{array}{l}33.3 \\
38.7 \\
50.2 \\
58.7\end{array}$ & & & $\begin{array}{l}31.4 \\
33.0 \\
44.7 \\
50.4\end{array}$ \\
\hline
\end{tabular}

${ }^{\mathrm{a}}$ High resolution shell is shown in parentheses.

${ }^{\mathrm{b}} R_{\text {merge }}=\sum|I-<I>| / \sum I$, where $<I>$ is the average intensity from multiple observations of symmetry-related reflections.

${ }^{\mathrm{c}} R_{\text {Cullis }}=\left[<(\mathrm{LOC})^{2}>\right]^{1 / 2}\left(<|\Delta \mathrm{F}|^{2}>\right)^{1 / 2}$, where LOC is the lack-of-closure error.

${ }^{\mathrm{d}}$ Before and after density modification.

${ }^{\mathrm{e}} R_{\text {work }}$ and $R_{\text {free }}=\sum_{\mathrm{h}}{ }_{\mathrm{h}}\left|F_{\mathrm{o}}\right|-\left|F_{\mathrm{c}} \| / \sum_{\mathrm{h}}\right| F_{\mathrm{o}} \mid$, where $F_{\mathrm{o}}$ and $F_{\mathrm{c}}$ are the observed and calculated structure factor amplitudes. $R_{\text {free }}$ was calculated with $10 \%$ of the reflections not used in refinement.

$0.6 \mu \mathrm{l}$ of protein $(16 \mathrm{mg} / \mathrm{ml})$ with $0.6 \mu 1$ reservoir solution $\left(25 \%\right.$ w/v PEG $3350,0.2 \mathrm{M} \mathrm{MgCl}_{2}, \quad 0.1 \mathrm{M}$ Tris-HCl $\mathrm{pH}$ 8.5) (Hampton Research Index Screen, condition 85) and equilibrated against $160 \mu \mathrm{l}$ reservoir buffer. Subsequently, crystals were obtained by streak seeding hanging drops with a protein concentration of $6 \mathrm{mg} / \mathrm{ml}$. Hanging drops were set up by mixing $1 \mu l$ of protein with $1 \mu \mathrm{l}$ of reservoir solution under the same crystallization conditions. Trigonal crystals grew to a maximum length of $200 \mu \mathrm{m}$ in space group $\mathrm{P} 3{ }_{1} 21\left(\mathrm{P}_{2} 21\right)$ with unit cell parameters $a=b=80.11 \AA, c=72.21 \AA$ and $\gamma=120^{\circ}$. There is one molecule per asymmetric unit with an estimated solvent content of $52 \%$. Crystals of the complex with $\mathrm{Ap}_{4} \mathrm{~A}$ were obtained with the hanging drop method. The hanging drops were set up manually by mixing $1 \mu$ of protein with $1 \mu 1$ of reservoir solution $(25 \% \mathrm{w} / \mathrm{v}$ PEG $3350,0.025 \mathrm{M} \mathrm{MgCl}_{2}, 0.1 \mathrm{M}$ Tris- $\mathrm{HCl} \mathrm{pH}$ 7.5). The drops were streak seeded after a $24 \mathrm{~h}$ incubation period. When the crystals reached at least $100 \mu \mathrm{m}, \mathrm{Ap}_{4} \mathrm{~A}$ at a final concentration of $44 \mathrm{mM}$ was added directly to the drop. After $6 \mathrm{~h}$ the soaked $\mathrm{Ap}_{4} \mathrm{~A}$ crystals were cryoprotected by the addition of $1 \mu 1$ of $25 \%(\mathrm{w} / \mathrm{v})$ PEG 3350 and $50 \%(\mathrm{v} / \mathrm{v})$ glycerol to the $2 \mu$ l hanging drop prior to flash cooling in liquid nitrogen.

\section{Crystallographic data collection}

Multiple wavelength anomalous diffraction (MAD) data were collected at beamline 23-ID-D (Advanced Photon Source at Argonne National Laboratory) on a MAR m300 CCD detector. One complete selenomethionyl MAD dataset was collected on one crystal at the peak, inflection and high-energy remote wavelengths to a maximum resolution of $1.85 \AA$. Data were collected at $1.80 \AA$ resolution on the $\mathrm{Ap}_{4} \mathrm{~A}$ complex at beamline X12B (National Synchrotron Light Source) on a Quantum-4 CCD (ADSC) detector. The data from three $\mathrm{Ap}_{4} \mathrm{~A}$-soaked crystals were merged to increase redundancy. Diffraction data were processed and scaled with DENZO and SCALEPACK (15). Data collection statistics are summarized in Table 1.

\section{Structure determination and refinement}

The program SOLVE (16) identified three of the four selenium sites (the $\mathrm{N}$-terminal methionine is disordered or 
missing). AutoSHARP (17) was then used for refinement of the selenium parameters. The space group was judged to be $\mathrm{P} 3_{1} 21$ and not the enantiomorphic $\mathrm{P} 3_{2} 21$, based on the map quality and continuity. The phasing information was then used in RESOLVE (18) for density modification and iterative model building. Seventy percent of the model was built by RESOLVE. The remaining residues were built manually using the program COOT (19). Residues 1-20 and 132-135 were omitted from the model because of poorly defined density.

Iterative rounds of refinement including simulated annealing, energy minimization, and B-factor refinement were done with CNS (20). Each refinement round was followed by rebuilding in COOT. A composite simulated annealing omit map was generated in CNS to validate the model and build the remaining side chains. Water molecules were added with CNS and COOT. The quality of the model was evaluated with PROCHECK (21). All non-glycine residues fall within either the most favored or additionally allowed regions of the Ramachandran plot. The refined model of the unliganded protein provided phases to calculate an isomorphous difference Fourier ( $\mathrm{Fo}-\mathrm{Fo})$ map between the unliganded protein and the complex with $\mathrm{Ap}_{4} \mathrm{~A}$ (22). The $R_{\text {cross }}$ on amplitudes between the two datasets is 0.149 , indicating good isomorphism between the two crystals. The resulting map showed clear density for one adenine base and three phosphates of $\mathrm{Ap}_{4} \mathrm{~A}$. The complex with $\mathrm{Ap}_{4} \mathrm{~A}$ was refined with CNS (20). The refinement statistics for both structures are reported in Table 1. Figures were drawn with PyMOL (23).

\section{Oligomeric state determination}

Size exclusion chromatography was performed with a Superdex 75 column (GE Healthcare). The protein sample or molecular mass standards were applied to the Superdex 75 column and eluted with $10 \%$ glycerol, $20 \mathrm{mM}$ Tris pH 7.5 and $50 \mathrm{mM} \mathrm{KCl}$. Standard proteins (Sigma) were: lysozyme (MW $14.4 \mathrm{kDa})$, egg albumin $(45 \mathrm{kDa})$, bovine serum albumin $(67 \mathrm{kDa})$ and the void volume was determined with blue dextran (GE Healthcare). Dynamic light scattering was also used to confirm the oligomeric state of CF $\mathrm{I}_{\mathrm{m}} 25$ (Dynapro, Wyatt). The buried surface area $\left(2800 \AA^{2}\right)$ was calculated with AREAIMOL (24) and with CNS $(20)\left(2700 \AA^{2}\right)$.

\section{Hydrolase activity assay}

The standard reaction mixture contained $50 \mathrm{mM}$ Tris$\mathrm{HCl}$, pH 7.5 or $8.5,50 \mathrm{mM} \mathrm{KCl}, 5 \mathrm{mM} \mathrm{MgCl} 2,1 \mathrm{mM}$ DTT, $20 \mu \mathrm{M}$ CF $\mathrm{I}_{\mathrm{m}} 25,2 \mathrm{U}$ calf intestinal phosphatase (New England Biolabs) or 1 U S. cerevisiae pyrophosphatase (Sigma), and 2 or $4 \mathrm{mM}$ substrate in a total volume of $50 \mu \mathrm{l}$. The putative substrates tested for $\mathrm{CF}$ $\mathrm{I}_{\mathrm{m}} 25$ hydrolase activity include ATP, $\mathrm{Ap}_{4} \mathrm{~A}$ (Sigma) and $\mathrm{m}^{7} \mathrm{G}\left(5^{\prime}\right) \mathrm{ppp}\left(5^{\prime}\right) \mathrm{G}$ cap structure analog (New England Biolabs). The reactants were combined at $4^{\circ} \mathrm{C}$ then incubated at $25^{\circ} \mathrm{C}$ for 30 and $60 \mathrm{~min}$. The reaction was terminated by the addition of $250 \mu \mathrm{l}$ of $20 \mathrm{mM}$ EDTA and the liberated orthophosphate was determined by the colorimetric assay of Ames and Dubin (9,25). The limit of detection of this assay is $5 \mu \mathrm{M}$ of orthophosphate.

\section{Fluorescence measurements}

Steady-state tryptophan fluorescence was measured with a Quantamaster fluorimeter (Photon Technology International, South Brunswick, NJ) as described (26) with a WG320 cut-off emission filter. CF $\mathrm{I}_{\mathrm{m}} 25$ contains four tryptophans and only three are built in the structure: Trp148 and Trp149 are within $10-15 \AA$ of the active site and Trp139 is located within $20 \AA$ of the active site. The fourth tryptophan, Trp13, is located in the disordered portion of the amino terminus. The tryptophan emission spectrum was measured by excitation of the samples at $295 \mathrm{~nm}$ and collecting the emitted fluorescence at $90^{\circ}$ to the incident light over the range $300-400 \mathrm{~nm}$. The slit widths were set at a resolution of $1 \mathrm{~nm}$ for excitation and $4 \mathrm{~nm}$ for emission. Fluorescence measurements of all protein samples were performed using a microcuvettte

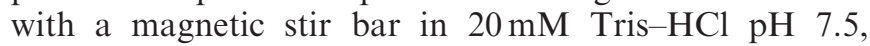
$50 \mathrm{mM} \mathrm{KCl}$ and $25 \mathrm{mM} \mathrm{MgCl}_{2}$ at $25^{\circ} \mathrm{C}$ for the protein alone and in the presence of increasing amounts of nucleotide. All fluorescence measurements were corrected for Raman scatter and background fluorescence and represent experiments performed in triplicate and then normalized and averaged. The ATP fluorescence data were fit with a single hyperbola $[y=a x /(b+x)]$ with a $K_{\mathrm{d}}$ of $1.53 \pm 0.18 \mathrm{mM}(1.17-1.89 \mathrm{mM}$ at $95 \%$ confidence interval). The $\mathrm{Ap}_{4} \mathrm{~A}$ data were fitted with a single hyperbola $[y=a x /(b+x)]$ with a $K_{\mathrm{d}}$ of $2.44 \pm 0.49 \mu \mathrm{M}$ (1.46-3.43 $\mu \mathrm{M}$ at $95 \%$ confidence interval).

\section{RESULTS}

\section{Crystal structure of human $C F I_{m} 25$}

The original N-terminal His-tagged plasmid of human CF $\mathrm{I}_{\mathrm{m}} 25$ (7) did not express to high enough levels for structural studies. We therefore inserted the coding sequence of CF $\mathrm{I}_{\mathrm{m}} 25$ into a dual HisMBP vector (13). With the resulting expression vector, $1.5 \mathrm{mg}$ of protein could be purified from 11 of culture. The structure was solved to a resolution of $1.85 \AA$ by multiple wavelength anomalous diffraction of the selenomethionyl protein variant. Residues $21-131$ and 136-227 are visible in the electron density map. A complex with $\mathrm{Ap}_{4} \mathrm{~A}$ was also obtained and refined to a resolution of $1.80 \mathrm{~A}$.

\section{Description of the structure}

Human CF $\mathrm{I}_{\mathrm{m}} 25$ is composed of 227 residues, with a calculated molecular weight of $26 \mathrm{kDa}$. $\mathrm{CF}_{\mathrm{m}} 25$ elutes as a dimer in gel exclusion chromatography with an apparent molecular weight of $\sim 53 \mathrm{kDa}$ (Supplementary Figure). The dimeric state of CF $\mathrm{I}_{\mathrm{m}} 25$ has also been confirmed by dynamic light scattering. In the crystal structure, dimer formation relates two monomers by a 2-fold crystallographic axis. The Nudix domain is located in the middle of the protein and spans residues 77-202 (Figure 2). The Nudix fold comprises two mixed $\beta$ sheets flanked by two helices ( $\alpha 2$ and $\alpha 3$ ). The Nudix box is located in helix $\alpha 2$ 


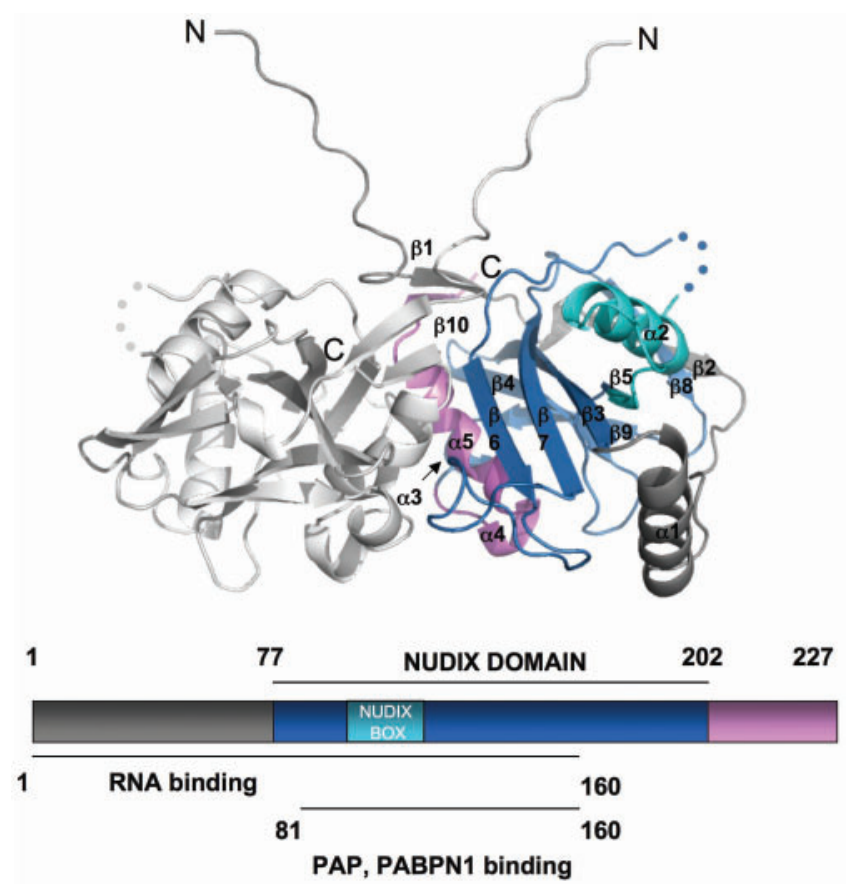

Figure 2. Domain organization of $\mathrm{CF}_{\mathrm{m}} 25$. Ribbon diagram of the $\mathrm{CF}$ $\mathrm{I}_{\mathrm{m}} 25$ dimer comprising residues $21-131$ and 136-227. The ribbon color scheme corresponds to that of the domain architecture shown below. The second monomer on the left is shown in light grey. The secondary structure numbering is based on a DSSP analysis (45).

(residues 109-131) and the preceding loop. The region immediately preceding the Nudix domain (residues 21-76) folds into two distinct segments: residues $21-32$ form an extended loop structure that projects away from the globular domain of the protein (residues 1-20 are not visible in the electron density map). The extended loop is stabilized via crystal-packing interactions with a symmetry-related monomer and this region, which has been shown to participate in RNA binding, is likely to adopt a different fold in vivo (7). Lys23 has previously been shown to undergo acetylation, a modification which modulates the interaction of $C F \mathrm{I}_{\mathrm{m}} 25$ with PAP (27). The second segment of the $\mathrm{N}$-terminal region (residues 33-76) contributes two short $\beta$ strands and a long helix. Within this region an additional modification, this time phosphorylation, was reported for Tyr40 (28). We do not see either modification because the protein was expressed in $E$. coli. The C-terminal region (residues 203-227) is composed of two helices $(\alpha 4$ and $\alpha 5)$ and a short beta strand $(\beta 10)$ comprising the final four residues.

Structural homologs of CF $\mathrm{I}_{\mathrm{m}} 25$ were searched with the DALI server (29) and significant structural homology was found, but only with other Nudix proteins, including Deinococcus radiodurans DR1025 $[Z$ score $=11.2$, PDB ID code 1SJY; (12)], $\mathrm{Ap}_{4} \mathrm{~A}$ hydrolase $[Z$ score $=10.0$, PDB ID code 1KT9; (30)], ADP ribose pyrophosphatase $[Z$ score $=9.3$; PDB ID code $1 \mathrm{~V} 8 \mathrm{M}$; (31) $]$ and the mRNA decapping enzyme DCP2P $[Z$ score $=9.0$; PDB ID code 2A6T; (32)]. The highest $Z$-score (33.6 with associated rmsd of $0.6 \AA$ ) was actually that of another crystal structure of CF $\mathrm{I}_{\mathrm{m}} 25$ for which coordinates were deposited but had no publication associated with it (Structural Genomics Consortium, Karolinska Institute; PDB ID code 2CL3).

\section{Dimer interactions}

Dimer formation buries an interface of about $2700 \AA^{2}$ $(20,24)$. The buried surface is extensive and represents $13 \%$ of the surface of the homodimer. The dimer interface is maintained by approximately 20 residues per monomer, which participate in both hydrogen bonding and nonpolar contacts. The monomer interactions are facilitated by the amino terminal extension (residues 21-32) and by helix $\alpha 5$, the loop preceding helix $\alpha 5$, helix $\alpha 6$, beta strand $\beta 6$, the loop linking $\beta 6$ and $\beta 7$ and beta strand $\beta 10$.

The main hydrogen-bonding contributions are between the amino terminal extension, beta strand $\beta 6$ and beta strand $\beta 10$. These involve residues Thr32 of chain A and Asp142 of chain B, Ser220 of chain A and Asn 147 of chain $\mathrm{B}$ as well as the reverse monomer interactions. The loop preceding helix $\alpha 5$ and the loop between $\beta 6$ and $\beta 7$ contribute to dimer formation through hydrophobic contacts involving residues Pro159 and Tyr160 from chain A and Tyr202 and Phe199 from chain B. Additional interactions are provided by stacking helix $\alpha 5$ from one monomer on to strand $\beta 6$ of the opposing monomer in a tail-to-tail fashion allowing hydrogen bonding between residues in the loop following helix $\alpha 5$. These hydrogen-bonding interactions include Arg221 and its symmetry mate and the carboxyl group of Ser220 with Asn147 from the opposing monomers.

\section{Metal binding}

CF $I_{m} 25$ is missing the second and fourth conserved glutamates of the Nudix box (residues 124 and 128), which are replaced by a leucine and isoleucine, respectively. These glutamate residues are very often involved in metal binding (12). We therefore set out to investigate whether CF $\mathrm{I}_{\mathrm{m}} 25$ was still capable of binding metal via the two remaining carboxylates. Although the $\mathrm{CF} \mathrm{I}_{\mathrm{m}} 25$ crystals were obtained in the presence of $200 \mathrm{mM} \mathrm{MgCl}$, there was no identifiable $\mathrm{Mg}^{2+}$ bound in the electron density map. Magnesium is a light atom, which is usually not easily identifiable in electron density maps and can often be mistaken for a water molecule. We therefore used metals that are more electron dense such as $\mathrm{MnCl}_{2}$ and $\mathrm{GdCl}_{3}$ to identify putative metal site(s) (33). $\mathrm{Mn}^{2+}$ and $\mathrm{Gd}^{3+}$ present the added advantage that they are anomalous scattering atoms, which should allow unambiguous identification of metal sites. We were unable to identify binding of either metal, regardless of whether the metal was co-crystallized or soaked into pre-existing crystals. Since Nudix enzymes require a divalent cation for catalysis (9), these experiments suggested that it is unlikely that $\mathrm{CF} \mathrm{I}_{\mathrm{m}} 25$ functions as a hydrolase. This finding called for further investigation of CF $\mathrm{I}_{\mathrm{m}} 25$ 's binding to potential substrates (see below).

\section{Enzymatic assays and substrate binding}

We next set out to investigate whether CF $\mathrm{I}_{\mathrm{m}} 25$ binds a substrate. We used three different methods: a colorimetric 
assay to measure the release of inorganic phosphate (25), co-crystallization/crystal soaking with putative substrates and steady-state tryptophan fluorescence experiments.

A colorimetric assay to measure the release of inorganic phosphate, and thus the potential hydrolytic activity of CF $\mathrm{I}_{\mathrm{m}} 25$ on nucleotides, was performed (25). The following putative substrates were tested: $\mathrm{ATP}, \mathrm{Ap}_{4} \mathrm{~A}$ and the $7 \mathrm{mG}\left(5^{\prime}\right) \mathrm{ppp}\left(5^{\prime}\right) \mathrm{G}$ cap analog. $\mathrm{Ap}_{4} \mathrm{~A}$ was chosen because the two enzymes found to be most structurally similar to CF $\mathrm{I}_{\mathrm{m}} 25$ bind $\mathrm{Ap}_{4} \mathrm{~A}(12,30)$. ATP and the cap analog were tested because of their prominent role in RNA processing. The assay indicated that, within the limits of detection of the assay, none of the putative substrates tested were hydrolyzed.

Although $\mathrm{CF}_{\mathrm{m}} 25$ does not seem to possess a hydrolytic activity, it could still bind nucleotides. Several putative ligands were either co-crystallized or soaked into the crystals: ATP, GTP, ADP, GDP, diadenosine triphosphate $\left(\mathrm{Ap}_{3} \mathrm{~A}\right), \mathrm{Ap}_{4} \mathrm{~A}, \mathrm{AMP}, 7 \mathrm{mG}\left(5^{\prime}\right) \mathrm{ppp}\left(5^{\prime}\right) \mathrm{G}$ cap analog, NAD + and GDP-mannose. In addition to testing these nucleotides, which are known substrates for Nudix enzymes, we also attempted to co-crystallize CF $\mathrm{I}_{\mathrm{m}} 25$ with a 21 mer RNA derived from the PAP $\gamma$ cDNA sequence $(4,5)$. Of all the putative ligands tested, only $\mathrm{Ap}_{4} \mathrm{~A}$ bound to the crystal (see later). The original crystallization conditions contained $200 \mathrm{mM} \mathrm{MgCl}_{2}$ and $25 \%$ (w/v) polyethylene glycol (PEG) 3350. Because nucleotides can precipitate in the presence of high concentrations of PEG and magnesium (34), care was taken to modify the crystallization conditions so as to decrease or completely eliminate $\mathrm{MgCl}_{2}$ and therefore lessen the risk of the nucleotide precipitating out of solution. Conditions with $\mathrm{NaCl}$ or even no salt could be used in lieu of $\mathrm{MgCl}_{2}$ to grow unliganded crystals. Even when the divalent cation was omitted from the crystallization solution crystals did not form with any of the ligands tested (with the notable exception of $\mathrm{Ap}_{4} \mathrm{~A}$ ), demonstrating that the lack of binding was not due to the nucleotide falling out of solution.

Binding studies were then performed employing the intrinsic tryptophan fluorescence properties of $\mathrm{CF} \mathrm{I}_{\mathrm{m}} 25$. The following Nudix ligands were tested: ATP, GTP, $\mathrm{Ap}_{4} \mathrm{~A}$, inositol hexaphosphate (IP6), $7 \mathrm{mG}\left(5^{\prime}\right) \mathrm{ppp}\left(5^{\prime}\right) \mathrm{G}$ cap analog, ADP and AMP. Dissociation constants $\left(K_{\mathrm{d}}\right)$ measured by titrating the ligand concentration were estimated for ATP and $\mathrm{Ap}_{4} \mathrm{~A}$ (Figure $3 \mathrm{~A}$ and $\mathrm{B}$, respectively). The ATP data were fit with a single hyperbola curve, indicating one binding affinity with a $K_{\mathrm{d}}$ value of $1.53 \pm 0.18 \mathrm{mM}$. The $\mathrm{Ap}_{4} \mathrm{~A}$-binding data were fit to a single hyperbola curve and represent one binding site per monomer, resulting in a $K_{\mathrm{d}}$ of $2.44 \pm 0.49 \mu \mathrm{M}$.

\section{Complex of $\mathrm{CF} \mathrm{I}_{\mathrm{m}} 25$ with $\mathrm{Ap}_{4} \mathrm{~A}$}

Co-crystallization experiments were performed in order to resolve the ligand-binding interactions of $\mathrm{CF} \mathrm{I}_{\mathrm{m}} 25$. Of all the molecules screened only $\mathrm{Ap}_{4} \mathrm{~A}$ was captured in a co-crystal (Figure $4 \mathrm{~A}$ ). The $\mathrm{Ap}_{4} \mathrm{~A}$ co-crystal structure was determined by using the phases from the unliganded structure. The resulting unbiased isomorphous difference Fourier $(\mathrm{Fo}-\mathrm{Fo})$ map revealed distinct density for one of
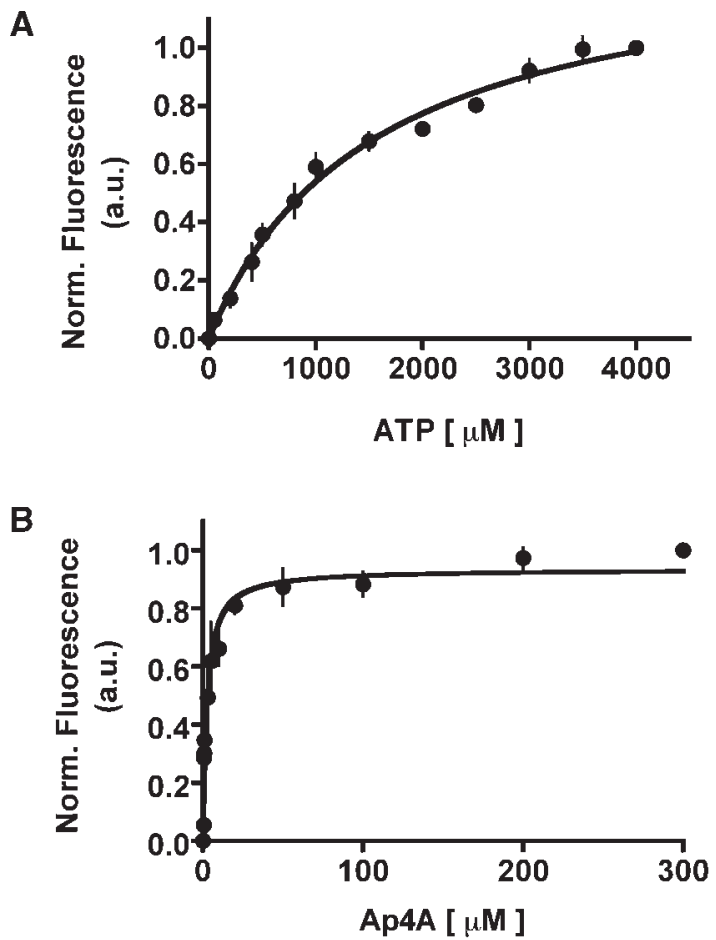

Figure 3. $\mathrm{CF} \mathrm{I}_{\mathrm{m}} 25$ steady-state tryptophan fluorescence experiments with ATP and $\mathrm{Ap}_{4} \mathrm{~A}$. All data are represented as normalized and averaged experiments done in triplicate. Error bars that are not represented lie within the symbol. (A) ATP steady-state tryptophan fluorescence data are fit with a single hyperbola, with $K_{\mathrm{d}}=1.53 \mathrm{mM}$. (B) $\mathrm{Ap}_{4} \mathrm{~A}$ steady-state tryptophan fluorescence data are fit with a single hyperbola, with $K_{\mathrm{d}}=2.44 \mu \mathrm{M}$.

the adenine bases and three of the four phosphates of $\mathrm{Ap}_{4} \mathrm{~A}$, in the cavity of $\mathrm{CF} \mathrm{I}_{\mathrm{m}} 25$ (Figure 4B). The rmsd between the bound and apo structures is low $(0.41 \AA)$, indicating that only very small changes take place upon substrate binding (20). The binding site residues Arg63, $\operatorname{Arg} 150$, Gln157 and Lys172 are found outside of the Nudix box region, within $3 \AA$ of the triphosphate moiety, and are involved in coordinating the triphosphate moiety (Figure 4B). The binding site is composed of residues from helix $\alpha 1$, beta strand $\beta 6$, the loop linking $\beta 6$ and $\beta 7$ and beta strand $\beta 7$. In CF $I_{m} 25$, Arg63 and Arg150 are highly conserved across species while Gln157 and Lys172 are moderately conserved. The majority of hydrogen-bonding interactions with $\mathrm{Ap}_{4} \mathrm{~A}$ involve the oxygens of the $\beta$ - and $\gamma$ phosphates. The ordered adenine base of the $\mathrm{Ap}_{4} \mathrm{~A}$ molecule stacks with Phe103, a residue contained within the Nudix domain. We note that the position of the $\gamma$ phosphate of $\mathrm{Ap}_{4} \mathrm{~A}$ coincides with the position of a sulfate ion reported for $\mathrm{CF} \mathrm{I}_{\mathrm{m}} 25$ (Structural Genomics Consortium, Karolinska Institute; PDB ID code 2J8Q).

CF $\mathrm{I}_{\mathrm{m}} 25$ has a core structure similar to that of the D. radiodurans Nudix protein DR1025 (12) (PDB ID code 1SU2) (Figure 5). Variations between these two structures arise from an extension in the loop linking $\beta 6$ and $\beta 7$, a shortening of the loop following $\beta 4$ and an additional $\alpha$-helix (helix $\alpha 1$ ) in the CF $\mathrm{I}_{\mathrm{m}} 25$ structure. The additional $\alpha$-helix in CF $\mathrm{I}_{\mathrm{m}} 25$ plays a role in sequestering the 
A

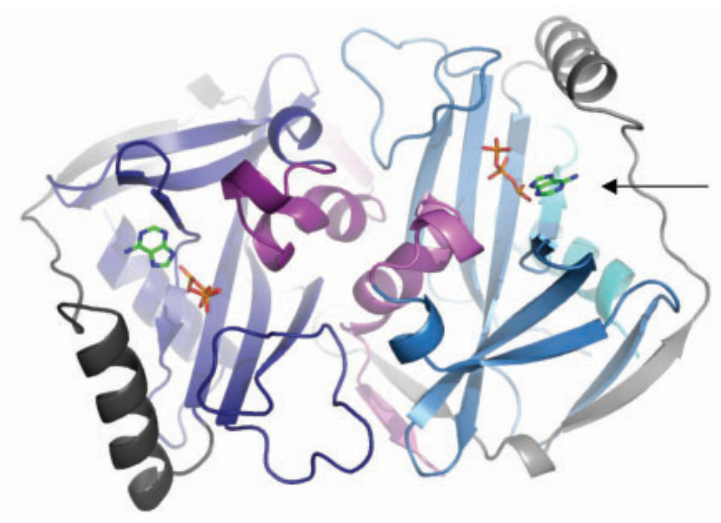

B

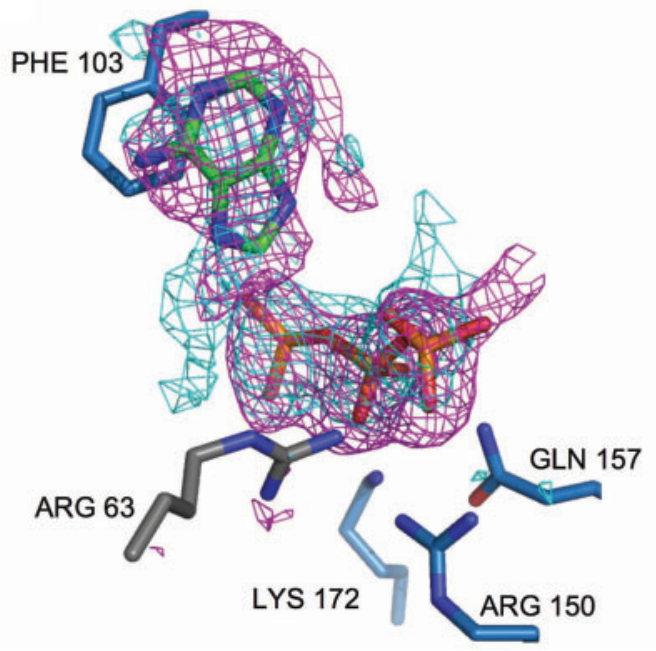

Figure 4. Complex of $\mathrm{CF}_{\mathrm{m}} 25$ and diadenosine tetraphosphate. (A) The arrow points to the position of $A_{4} A$ within the $C F I_{m} 25$ dimer shown rotated $120^{\circ}$ as compared to Figure 2. (B) The ordered moieties of $A_{4} A$ (adenine base and triphosphate) are superimposed on an original, unbiased $1.80 \AA$ (Fo-Fo) isomorphous difference Fourier map contoured at $2.6 \sigma$ (cyan) and a simulated annealing omit map contoured at $2.7 \sigma$ (magenta). The adenine base of $\mathrm{CF}_{\mathrm{m}} 25$ is stabilized through base stacking interaction with Phe103. Arg63, Arg150, Gln157 and Lys172 contact the oxygens of the $\beta$ and $\gamma$ phosphates.

substrate binding pocket from solvent exposure. When comparing the positions of the bound nucleotides between CF $\mathrm{I}_{\mathrm{m}} 25$ and DR1025 we also see variations in substrate fit. Superposition of the ATP bound in DR1025 on to the CF $\mathrm{I}_{\mathrm{m}} 25$ structure shows that both the base and phosphate tail would clash with protein residues in helix $\alpha 1$ and beta strand $\beta 5$ in the $\mathrm{CF} \mathrm{I}_{\mathrm{m}} 25$ structure (Figure 6). Commonly, variations in the nucleotide-binding region of Nudix proteins occur due to differences in the side chains and motifs and contribute to the substrate specificity of the Nudix protein. Interestingly, both DR1025 and CF $\mathrm{I}_{\mathrm{m}} 25$ stabilize the adenine base via stacking interactions with a phenylalanine residue found outside of the Nudix box region. Base-stacking interactions via a Tyr or Phe located 17 amino acids downstream of the Nudix box is commonly found in all of the Nudix $\mathrm{Ap}_{4} \mathrm{~A}$ hydrolases, including DR1025 (11). Phe103 stabilizes the adenine base in the $\mathrm{Ap}_{4} \mathrm{~A}$ bound $\mathrm{CF} \mathrm{I}_{\mathrm{m}} 25$ structure but is located six residues upstream of the Nudix box region.

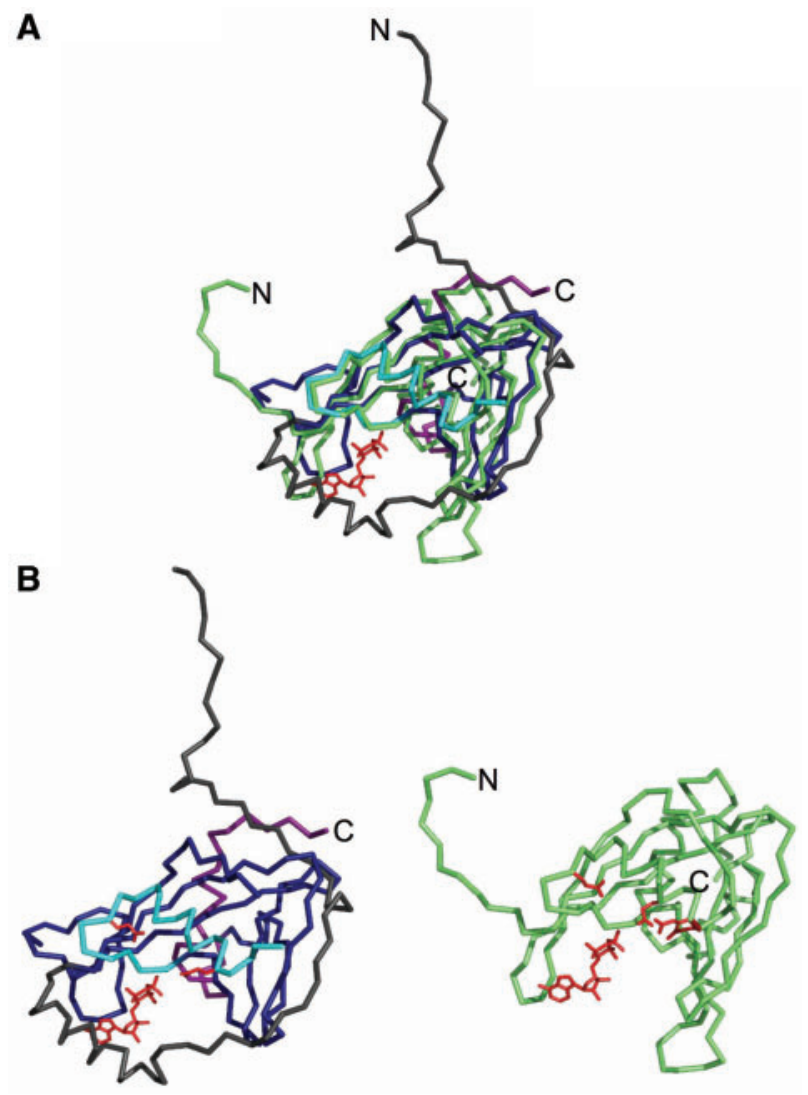

Figure 5. Comparison with other Nudix proteins. (A) Superposition of the Nudix regions between DR1025 (PDB ID code 1SU2) (12) and CF $\mathrm{I}_{\mathrm{m}} 25$ in their monomeric form. The superposition was calculated over residues $12-145$ in DR1025 and 77-202 in CF $\mathrm{I}_{\mathrm{m}} 25$. DR 1025 is shown in light green and its bound substrate (ATP) is colored in red. CF $\mathrm{I}_{\mathrm{m}} 25$ is colored according to its domain architecture as shown in Figure 2. (B) Side-by-side representation of the monomeric forms of the substrate bound DR 1025 and CF $\mathrm{I}_{\mathrm{m}} 25$ with ATP from the DR1025 structure and the conserved glutamate residues both shown in red.

\section{Electrostatic surface and putative RNA and protein-binding regions}

The electrostatic surface potential of $\mathrm{CF}_{\mathrm{m}} 25$ was calculated with GRASP (Figure 7A) (35). The amino terminal region and residues 78-160 of the Nudix domain were shown to participate in RNA binding (7). We observe a good correlation between the location of the putative RNA binding residues and that of the positively charged residues on the surface of the protein (Figure 7B).

\section{DISCUSSION}

In our crystal structure CF $\mathrm{I}_{\mathrm{m}} 25$ is a homodimer. A dimeric state for $\mathrm{CF}_{\mathrm{m}} 25$ is consistent with dynamic light scattering (DLS) and gel filtration experiments performed with the $25 \mathrm{kDa}$ subunit both unliganded and with ATP or $\mathrm{Ap}_{4} \mathrm{~A}$. The dimeric structure of $\mathrm{CF} \mathrm{I}_{\mathrm{m}} 25$ suggests that the active form of $C F I_{m}$ may be a heterotrimer composed of a CF $\mathrm{I}_{\mathrm{m}} 25$ homodimer and either the 59,68 or $72 \mathrm{kDa}$ subunit. This is consistent with interaction studies in C. elegans (DIP interaction database accession DIP:25083N) where the CF $\mathrm{I}_{\mathrm{m}} 25$ homolog (Uniprot accession Q93716) was 


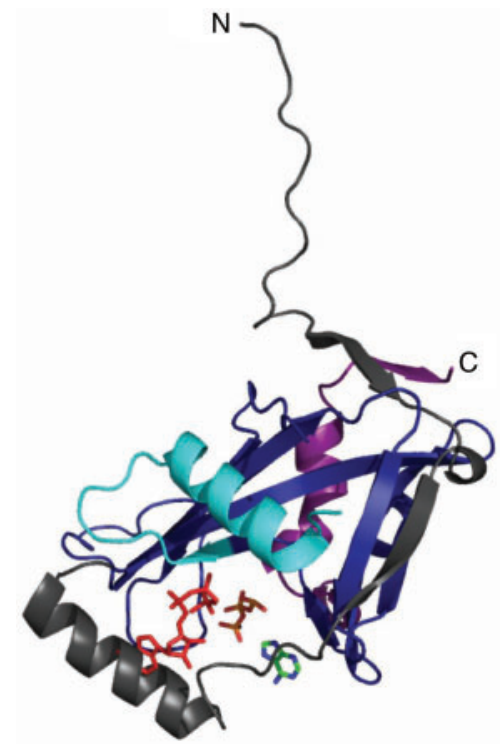

Figure 6. Positions of DR 1025 ATP and $A_{4} A$ in the $C F I_{m} 25$ structure. Positions of the DR1025 ATP shown in red and CF $\mathrm{I}_{\mathrm{m}} 25$ $\mathrm{Ap}_{4} \mathrm{~A}$ colored in orange (phosphates) and blue/green (adenine base) within the $C F I_{m} 25$ structure. Ligand position was determined by superposition of the Nudix region over residues $12-145$ in DR1025 (PDB ID code 1SU2) and 77-202 in CF $\mathrm{I}_{\mathrm{m}} 25$. Only one CF $\mathrm{I}_{\mathrm{m}} 25$ monomer is shown
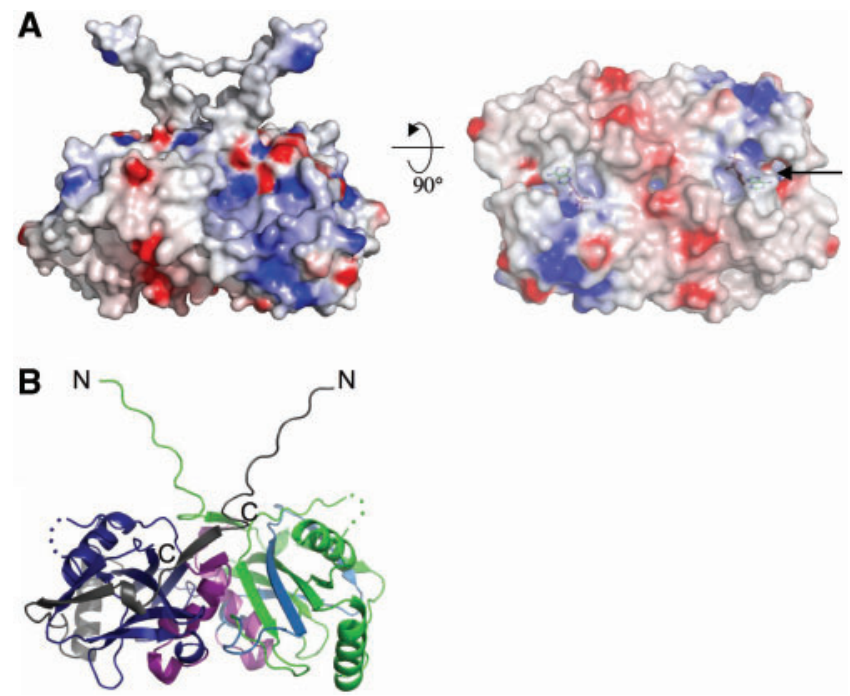

Figure 7. Surface representation of $\mathrm{CF}_{\mathrm{m}} 25$. (A) Electrostatic potential surface representation of dimeric CF $\mathrm{I}_{\mathrm{m}} 25$ calculated by the program GRASP (32). The surface is shown in the same orientation as in Figure 2 (left) and rotated $90^{\circ}$ (right). The surface on the right was made semi-transparent to show the bound $\mathrm{Ap}_{4} \mathrm{~A}$ (shown with arrow). The areas of negative charge are depicted in red, whereas the positively charged regions are colored in blue. (B) Ribbon diagram of dimeric $\mathrm{CF}$ $\mathrm{I}_{\mathrm{m}} 25$ in the same orientation as in $\mathbf{A}$, with residues 21-160 corresponding to the RNA-binding region highlighted in green.

found to interact with itself and with the CF $\mathrm{I}_{\mathrm{m}} 68$ homolog (Uniprot accession Q18937). Alternatively, the complex with the larger subunit of $\mathrm{CF} \mathrm{I}_{\mathrm{m}}$ could be a heterotetramer. A third possibility is that $\mathrm{CF} \mathrm{I}_{\mathrm{m}} 25$ monomerizes upon binding the larger subunit.
The Nudix box of $\mathrm{CF} \mathrm{I}_{\mathrm{m}} 25$ lacks two of the four glutamates important for catalytic function and metal binding. Our structural and biochemical characterization suggests that $C F I_{m} 25$ is able to bind but not hydrolyze nucleotide substrates. In the dinucleotide bound $\mathrm{CF} \mathrm{I}_{\mathrm{m}} 25$ structure, the dinucleotide is found outside of the Nudix box and lies deeper within the active site compared to ATP in DR1025. The fluorescence-binding data for CF $\mathrm{I}_{\mathrm{m}} 25$, indicate a binding affinity in the low micromolar range for $\mathrm{Ap}_{4} \mathrm{~A}$ indicative of a potential role as a signaling molecule and a weak, albeit physiologically relevant, binding affinity for ATP. Even though $\mathrm{CF} \mathrm{I}_{\mathrm{m}} 25$ binds both $\mathrm{Ap}_{4} \mathrm{~A}$ and ATP, we have so far only been able to obtain a co-crystal complex with $\mathrm{Ap}_{4} \mathrm{~A}$. It is entirely possible that the crystallization conditions we have explored to date for the protein-ATP complex are not compatible with the formation of a crystal lattice and that further exploration of the crystallization space might yield the desired conditions. We note that pre-formed crystals of CF $\mathrm{I}_{\mathrm{m}} 25$ dissolve upon addition of ATP, indicating a possible conformation change upon binding of the nucleotide.

To our knowledge, CF $\mathrm{I}_{\mathrm{m}} 25$ is the first example of a Nudix protein binding and not hydrolyzing a nucleotide substrate. This loss of function/gain of a regulatory role is not unprecedented in evolution. A similar loss of function was reported for the Lactobacillus lactis ATP phosphoribosyl transferase (ATP-PRT) regulatory subunit, His Z (36). ATP-PRT functions to initiate the biosynthesis of histidine and requires both the HisZ subunit and HisG, the catalytic subunit, for activity. The regulatory subunit, HisZ, resembles the catalytic domain of functional histidyl-tRNA synthetases (HisRS) and utilizes its fold, not for catalysis, but for binding of histidine to monitor histidine levels. Although there were no metals evident in either the free or bound structures of $\mathrm{CF} \mathrm{I}_{\mathrm{m}} 25$ and no identifiable hydrolytic activity in our colorimetric assay it remains possible that the Nudix box of $C F \mathrm{I}_{\mathrm{m}} 25$ could potentiate hydrolysis of $\mathrm{Ap}_{4} \mathrm{~A}$ and ATP upon interaction of $\mathrm{CF} \mathrm{I}_{\mathrm{m}} 25$ with one of the larger $\mathrm{CF} \mathrm{I}_{\mathrm{m}}$ subunits or additional binding partners.

$\mathrm{Ap}_{4} \mathrm{~A}$ belongs to the family of diadenosine oligophosphates, $A p_{n} A$, which were first discovered 40 years ago $(37,38) . \mathrm{Ap}_{4} \mathrm{~A}$ is composed of two adenosines and four phosphates linked in $5^{\prime}$ to $5^{\prime}$-phosphodiester linkages. The role of $A p_{n} A s$ in higher eukaryotes has remained elusive. Recently, $A p_{n} A s$ have been suggested to play a role as putative extra- and intracellular signaling molecules. $\mathrm{Ap}_{4} \mathrm{~A}$ itself is involved in the cellular stress response, inhibition of $\mathrm{K}_{\mathrm{ATP}}$ channels, stimulation of DNA replication and repair, as well as influencing other essential cellular processes in eukaryotes $(37,38)$. Presently, the only link between $\mathrm{Ap}_{4} \mathrm{~A}$ and $3^{\prime}$-end processing was described in yeast where stimulation of primer independent synthesis by yeast poly(A) polymerase was observed in the presence of dinucleoside polyphosphates, including $\mathrm{Ap}_{4} \mathrm{~A}$ (39). There is no CF $\mathrm{I}_{\mathrm{m}} 25$ homolog in yeast but this observation still suggests a potential role for dinucleoside polyphosphates as signaling molecules during RNA-processing events. The concentration of ATP and $\mathrm{Ap}_{4} \mathrm{~A}$ can fluctuate within the cell in response to cellular stress or growth. 
Preliminary experiments on the role of $\mathrm{Ap}_{4} \mathrm{~A}$ during the polyadenylation step of $3^{\prime}$-end processing resulted in a non-competitive inhibition of polyadenylation in a poly (A) extension assay with mammalian PAP (results not shown). This suggests that under conditions of high concentrations of $\mathrm{Ap}_{4} \mathrm{~A}$ such as stress, $\mathrm{Ap}_{4} \mathrm{~A}$ can bind to a site in PAP, other than the ATP binding site, to inhibit polyadenylation.

The residues $81-160$ of the Nudix domain play a dual role, binding RNA and stabilizing protein-protein interactions. Additionally, the amino terminus (1-76) participates in RNA binding (Figure 2) (7). A stable interaction between $C F \mathrm{I}_{\mathrm{m}} 25$ and $\mathrm{CF} \mathrm{I}_{\mathrm{m}} 68$, unlike that involving PAP or PABPN1, requires the entire CF $\mathrm{I}_{\mathrm{m}} 25$ protein. $\mathrm{CF} \mathrm{I}_{\mathrm{m}} 68$ must contact regions outside of the known RNA-binding region of $\mathrm{CF} \mathrm{I}_{\mathrm{m}} 25$ to promote complex formation and stimulate pre-mRNA $3^{\prime}$-end processing. Interestingly, CF $\mathrm{I}_{\mathrm{m}} 25$ has a patch of negatively charged surface residues that runs the length of the dimer interface (Figure 7A). This charged region is composed of residues primarily from beta strand $\beta 3$ and helix $\alpha 4$ and could potentiate protein-protein interactions with $\mathrm{CF} \mathrm{I}_{\mathrm{m}} 25$ 's other binding partners, possibly $\mathrm{CF} \mathrm{I}_{\mathrm{m}} 68$. Also intriguing is the observation that a binding interaction between the substrate RNA and the $25 \mathrm{kDa}$ subunit occurs in the absence of a putative RNA-binding domain. This suggests another mechanism of RNA recognition, possibly through homodimer formation. A CF $\mathrm{I}_{\mathrm{m}} 25$ homodimer may enhance the binding potential to the RNA substrate compared to a monomer interaction by increased surface area interactions. A definite answer regarding the oligomeric state of the $25 \mathrm{kDa}$ subunit and the RNA-binding mechanism will have to await a CF $\mathrm{I}_{\mathrm{m}} 25$ structure with RNA bound.

The results reported here suggest that $C F \mathrm{I}_{\mathrm{m}} 25$ is unable to hydrolyze nucleotides or dinucleotides even though it harbors a classic Nudix fold. The Nudix domain of CF $\mathrm{I}_{\mathrm{m}} 25$ may instead facilitate protein-protein interactions, as suggested by the large distribution of charged residues in the electrostatic surface representation of the Nudix domain. This charge distribution of the Nudix domain correlates well with results from pull-down experiments with PAP and PABPN1 (7).

The interaction of CF $\mathrm{I}_{\mathrm{m}}$ with the RNA substrate and with PAP stimulates the rate of polyadenylate tail synthesis. This may be facilitated by the binding of ATP to $C F \mathrm{I}_{\mathrm{m}} 25$. Preliminary data (S. Dettwiler and W. Keller, unpublished) showed that $\mathrm{CF} \mathrm{I}_{\mathrm{m}} 25$ interacts with hClp1, a protein shown to bind ATP which is involved in 3'-premRNA processing and tRNA splicing $(40,41)$. This observation, in conjunction with the fact that hClp1 has recently been shown to function as an siRNA kinase and a kinase that phosphorylates the $5^{\prime}$-end of the $3^{\prime}$-splicing product in human tRNA splicing (42), suggests a possible link between $C F \mathrm{I}_{\mathrm{m}} 25$ 's binding of ATP and proteinprotein cross talk. Recently, $\mathrm{CF} \mathrm{I}_{\mathrm{m}} 25$ has also been shown to be associated in a large RNP complex with Rae1, an mRNA export protein, in the nucleation and stabilization of microtubules during spindle assembly (43). This interaction is via $C F \mathrm{I}_{\mathrm{m}} 25$ association with an RNA component of the RNP complex and suggests a role for CF $\mathrm{I}_{\mathrm{m}} 25$ in mRNA export via direct RNA association that may be influenced by the concentration of intracellular nucleotides or dinucleotides.

\section{SUPPLEMENTARY DATA}

Supplementary Data are available at NAR Online.

\section{ACKNOWLEDGEMENTS}

This work was supported by National Institutes of Health grant GM62239 to SD and a Department of Energy Experimental program to Stimulate Competitive Research predoctoral fellowship to M.C. Work in the laboratory of W.K. was supported by the University of Basel and the Swiss National Science Foundation. The beamline at Advanced Photon Source at Argonne National Laboratory (GM/CA-CAT) has been funded in whole or in part with federal funds from National Cancer Institute Grant Y1-CO-1020 and National Institute of General Medical Science Grant Y1-GM-1104. The beamline at the National Synchrotron Light Source, Brookhaven National Laboratory, was supported by the U.S. Department of Energy, Office of Science, Office of Basic Sciences, under Contract No. DE-AC02-98CH10886. We are grateful to Dr David Waugh (NIH) for his generous gift of the dual His-MBP vector and the Tev protease plasmid. We thank Justin Meyette for helpful discussions concerning protein purification and Dr Mark A. Rould, Dr Pierre Aller, Dylan Murray and Karl Zahn for help with data collection and refinement, and Dr Mark A. Rould for help with troubleshooting the fluorescence experiments. Coordinates and structure factor amplitudes have been deposited in the Protein Data Bank with entry codes $3 \mathrm{BAP}$ and $3 \mathrm{BHO}$ for the unliganded and $\mathrm{Ap}_{4} \mathrm{~A}$ bound structures, respectively. Funding to pay the Open Access publication charges for this article was provided by NIH.

Conflict of interest statement. None declared.

\section{REFERENCES}

1. Zhao,J., Hyman,L. and Moore,C. (1999) Formation of mRNA $3^{\prime}$ ends in eukaryotes: mechanism, regulation, and interrelationships with other steps in mRNA synthesis. Microbiol. Mol. Biol. Rev., 63, 405-445.

2. Wahle,E. and Rüegsegger,U. (1999) 3' End processing of pre-mRNA in eukaryotes. FEMS Microbiol. Rev., 23, 277-295.

3. Minvielle-Sebastia,L. and Keller,W. (1999) mRNA polyadenylation and its coupling to other RNA processing reactions and to transcription. Curr. Opin. Cell Biol., 11, 352-357.

4. Brown,K.M. and Gilmartin,G.M. (2003) A mechanism for the regulation of pre-mRNA $3^{\prime}$ processing by human cleavage factor Im. Mol. Cell, 12, 1467-1476.

5. Venkataraman,K., Brown,K.M. and Gilmartin,G.M. (2005) Analysis of a noncanonical poly(A) site reveals a tripartite mechanism for vertebrate poly(A) site recognition. Genes Dev., 19, 1315-1327.

6. Rüegsegger,U., Beyer,K. and Keller,W. (1996) Purification and characterization of human cleavage factor Im involved in the $3^{\prime}$ end processing of messenger RNA precursors. J. Biol. Chem., 271, 6107-6113.

7. Dettwiler,S., Aringhieri,C., Cardinale,S., Keller,W. and Barabino,S.M. (2004) Distinct sequence motifs within the $68-\mathrm{kDa}$ subunit of cleavage factor Im mediate RNA binding, 
protein-protein interactions, and subcellular localization. J. Biol. Chem., 279, 35788-35797.

8. Millevoi,S., Loulergue,C., Dettwiler,S., Karaa,S.Z., Keller,W., Antoniou,M. and Vagner,S. (2006) An interaction between U2AF 65 and $\mathrm{CF} I(\mathrm{~m})$ links the splicing and $3^{\prime}$ end processing machineries. EMBO J., 25, 4854-4864.

9. Bessman,M.J., Frick,D.N. and O'Handley,S.F. (1996) The MutT proteins or "Nudix" hydrolases, a family of versatile, widely distributed, "housecleaning" enzymes. J. Biol. Chem., 271, 25059-25062.

10. Mildvan,A.S., Xia,Z., Azurmendi,H.F., Saraswat,V., Legler,P.M., Massiah,M.A., Gabelli,S.B., Bianchet,M.A., Kang,L.W. et al. (2005) Structures and mechanisms of Nudix hydrolases. Arch. Biochem. Biophys., 433, 129-143.

11. McLennan,A.G. (2006) The Nudix hydrolase superfamily. Cell. Mol. Life Sci., 63, 123-143.

12. Ranatunga,W., Hill,E.E., Mooster,J.L., Holbrook,E.L., Schulze-Gahmen,U., Xu,W., Bessman,M.J., Brenner,S.E. and Holbrook,S.R. (2004) Structural studies of the Nudix hydrolase DR1025 from Deinococcus radiodurans and its ligand complexes. J. Mol. Biol., 339, 103-116.

13. Tropea,J.E., Cherry,S., Nallamsetty,S., Bignon,C. and Waugh,D.S (2007) In Doublié,S. (ed.), Macromolecular Crystallography Protocols. Humana Press, Totowa, Vol. 1, pp. 1-20.

14. Doublié,S. (2007) In Doublié,S. (ed.), Macromolecular Crystallography Protocols. Humana Press, Totowa, Vol. 1, pp. $91-108$

15. Otwinowski,Z. and Minor,W. (1997) Macromolecular Crystallography, Part A. Academic press, New York, Vol. 276, pp. $307-326$

16. Terwilliger,T.C. and Berendzen,J. (1999) Automated MAD and MIR structure solution. Acta Crystallogr. D Biol. Crystallogr., 55, 849-861.

17. Vonrhein,C., Blanc,E., Roversi,P. and Bricogne,G. (2007) In Doublié,S. (ed.), Macromolecular Crystallography Protocols. Humana Press, Totowa, Vol. 1, pp. 215-230.

18. Terwilliger,T.C. (2000) Maximum-likelihood density modification. Acta Crystallogr. D Biol. Crystallogr., 56, 965-972.

19. Emsley,P. and Cowtan,K. (2004) Coot: model-building tools for molecular graphics. Acta Crystallogr. D Biol. Crystallogr., 60, 2126-2132.

20. Brunger,A.T., Adams,P.D., Clore,G.M., DeLano,W.L., Gros,P., Grosse-Kunstleve,R.W., Jiang,J.S., Kuszewski,J., Nilges,M. et al. (1998) Crystallography \& NMR system: a new software suite for macromolecular structure determination. Acta Crystallogr. D Biol. Crystallogr., 54, 905-921.

21. Laskowski,R.A., McArthur,M.W., Moss,D.S. and Thornton,J.M. (1993) PROCHECK: a program to check the stereochemical quality of protein structures. J. Appl. Cryst., 26, 283-291.

22. Rould,M.A. (2006) The same but different: isomorphous methods for phasing and high-throughput ligand screening. Methods Mol. Biol., 364, 159-182.

23. DeLano,W.L., The PyMOL Molecular Graphics System (2002) on the World Wide Web. http://www.pymol.org. San Carlos, CA, USA.

24. CCP4. (1994) The CCP4 suite: programs for protein crystallography. Acta Crystallogr. D Biol. Crystallogr., 50, 760-763.

25. Ames,B.N. and Dubin,D.T. (1960) The role of polyamines in the neutralization of bacteriophage deoxyribonucleic acid. J. Biol. Chem., 235, 769-775.

26. Yengo,C.M., Chrin,L.R., Rovner,A.S. and Berger,C.L. (2000) Tryptophan 512 is sensitive to conformational changes in the rigid relay loop of smooth muscle myosin during the MgATPase cycle. J. Biol. Chem., 275, 25481-25487.
27. Shimazu,T., Horinouchi,S. and Yoshida,M. (2007) Multiple histone deacetylases and the CREB-binding protein regulate pre-mRNA $3^{\prime}$ end processing. J. Biol. Chem., 282, 4470-4478.

28. Rush,J., Moritz,A., Lee,K.A., Guo,A., Goss,V.L., Spek,E.J., Zhang,H., Zha,X.M., Polakiewicz,R.D. et al. (2005) Immunoaffinity profiling of tyrosine phosphorylation in cancer cells. Nat. Biotechnol., 23, 94-101.

29. Holm,L. and Sander,C. (1997) Dali/FSSP classification of three-dimensional protein folds. Nucleic Acids Res., 25, 231-234.

30. Bailey,S., Sedelnikova,S.E., Blackburn,G.M., Abdelghany,H.M., Baker,P.J., McLennan,A.G. and Rafferty,J.B. (2002) The crystal structure of diadenosine tetraphosphate hydrolase from Caenorhabditis elegans in free and binary complex forms. Structure, 10, 589-600.

31. Yoshiba,S., Ooga,T., Nakagawa,N., Shibata,T., Inoue,Y., Yokoyama,S., Kuramitsu,S. and Masui,R. (2004) Structural insights into the Thermus thermophilus ADP-ribose pyrophosphatase mechanism via crystal structures with the bound substrate and metal. J. Biol. Chem., 279, 37163-37174.

32. She,M., Decker,C.J., Chen,N., Tumati,S., Parker,R. and Song,H (2006) Crystal structure and functional analysis of Dcp2p from Schizosaccharomyces pombe. Nat. Struct. Mol. Biol., 13, 63-70.

33. Gabelli,S.B., Bianchet,M.A., Bessman,M.J. and Amzel,L.M. (2001) The structure of ADP-ribose pyrophosphatase reveals the structural basis for the versatility of the Nudix family. Nat. Struct. Biol., 8, 467-472.

34. Logan,D.T., Andersson,J., Sjoberg,B.M. and Nordlund,P. (1999) A glycyl radical site in the crystal structure of a class III ribonucleotide reductase. Science, 283, 1499-1504.

35. Nicholls,A., Sharp,K.A. and Honig,B. (1991) Protein folding and association: insights from the interfacial and thermodynamic properties of hydrocarbons. Proteins, 11, 281-296.

36. Champagne,K.S., Sissler,M., Larrabee,Y., Doublie,S. and Francklyn,C.S. (2005) Activation of the hetero-octameric ATP phosphoribosyl transferase through subunit interface rearrangement by a tRNA synthetase paralog. J. Biol. Chem., 280 , 34096-34104

37. Kisselev,L.L., Justesen,J., Wolfson,A.D. and Frolova,L.Y. (1998) Diadenosine oligophosphates $(\mathrm{Ap}(\mathrm{n}) \mathrm{A})$, a novel class of signalling molecules? FEBS Lett., 427, 157-163.

38. Baxi,M.D. and Vishwanatha,J.K. (1995) Diadenosine polyphosphates: their biological and pharmacological significance. J. Pharmacol. Toxicol. Methods, 33, 121-128.

39. Sillero,M.A., De Diego,A., Osorio,H. and Sillero,A. (2002) Dinucleoside polyphosphates stimulate the primer independent synthesis of poly(A) catalyzed by yeast poly(A) polymerase. Eur. J. Biochem., 269, 5323-5329.

40. Noble,C.G., Beuth,B. and Taylor,I.A. (2007) Structure of a nucleotide-bound Clp1-Pcf11 polyadenylation factor. Nucleic Acids Res., 35, 87-99.

41. de Vries,H., Rüegsegger,U., Hübner,W., Friedlein,A., Langen,H. and Keller,W. (2000) Human pre-mRNA cleavage factor II (m) contains homologs of yeast proteins and bridges two other cleavage factors. EMBO J., 19, 5895-5904.

42. Weitzer,S. and Martinez,J. (2007) The human RNA kinase hClpl is active on $3^{\prime}$ transfer RNA exons and short interfering RNAs. Nature, 447, 222-226.

43. Blower,M.D., Nachury,M., Heald,R. and Weis,K. (2005) A Rael-containing ribonucleoprotein complex is required for mitotic spindle assembly. Cell, 121, 223-234.

44. Pearson,W.R. and Lipman,D.J. (1988) Improved tools for biological sequence comparison. Proc. Natl Acad. Sci. U.S.A, 85, 2444-2448.

45. Kabsch,W. and Sander,C. (1983) Dictionary of protein secondary structure: pattern recognition of hydrogen-bonded and geometrical features. Biopolymers, 22, 2577-2637. 